\title{
Robot carers, ethics, and older people
}

\author{
Tom Sorell · Heather Draper
}

Published online: 25 March 2014

(C) The Author(s) 2014. This article is published with open access at Springerlink.com

\begin{abstract}
This paper offers an ethical framework for the development of robots as home companions that are intended to address the isolation and reduced physical functioning of frail older people with capacity, especially those living alone in a noninstitutional setting. Our ethical framework gives autonomy priority in a list of purposes served by assistive technology in general, and carebots in particular. It first introduces the notion of "presence" and draws a distinction between humanoid multi-function robots and nonhumanoid robots to suggest that the former provide a more sophisticated presence than the latter. It then looks at the difference between lower-tech assistive technological support for older people and its benefits, and contrasts these with what robots can offer. This provides some context for the ethical assessment of robotic assistive technology. We then consider what might need to be added to presence to produce care from a companion robot that deals with older people's reduced functioning and isolation. Finally, we outline and explain our ethical framework. We discuss how it combines sometimes conflicting values that the design of a carebot might incorporate, if informed by an analysis of the different roles that can be served by a companion robot.
\end{abstract}

Keywords Robots - Ethics - Telecare - Assistive technology $\cdot$ Autonomy $\cdot$ Nature of care $\cdot$ ACCOMPANY

\section{T. Sorell}

Politics and International Studies, University of Warwick, Social Sciences, Gibbet Hill Road, Coventry CV4 7AL, UK

e-mail: T.E.Sorell@warwick.ac.uk

\section{H. Draper $(\bowtie)$}

Medicine, Ethics, Society and History (MESH), School of

Health and Population Sciences, University of Birmingham, 90,

Vincent Drive, Birmingham B152TT, UK

e-mail: h.draper@bham.ac.uk
What role might robots have in the future care at home of older people? That depends on the kind of robot and the aspects of ageing addressed. We argue that social robotsrepresented in our discussion by the Care-O-bot ${ }^{\circledR}-$ commendably integrate the functions of useful non-robotic telecare devices, and that they also have a claim to the potentially therapeutic property we call "presence". The relevant normative requirements that we discuss are mostly ethical, though they might also include value for money, and considerations about the range of physical environments in which the relevant technology can operate. The ethical framework we present in this paper was developed in the European Union-funded FP7 ACCOMPANY project, which has adapted the Care-O-bot ${ }^{\circledR}$ as a home companion for older people. ACCOMPANY scenarios primarily address the isolation and reduced physical functioning of some older people, especially those living alone in a non-institutional setting. Our ethical framework gives autonomy priority in a list of purposes served by assistive technology in general, and carebots in particular, for isolated and frail older people.

The paper consists of four sections. In the first, the capacity of robots to be "present" to their users is introduced. We argue that presence is a necessary condition for being a companion robot but a far from sufficient condition of being a carer or even of being a care-robot in a substantial sense of 'care'. In the second section we describe relatively low tech assistive technology and its benefits, and contrast these with what a robot can offer. The possible ethical problems of carebot design are then considered, on the basis of the review of recent carebot literature by Vallor (2011). This provides some context for the ethical assessment of robotic assistive technology. In the third section we consider what might need to be added to presence to produce care from a companion robot that deals with older people's 
reduced functioning and isolation. We distinguish between single-function and multi-function robots and what they can contribute to the care of older people in combination. Finally, we introduce an ethical framework that combines sometimes conflicting values that the design of a carebot might incorporate. The framework is informed by an analysis of the different roles that can be served by a companion robot, roles that are catered for in ACCOMPANY scenarios. Autonomy on the part of users is the pre-eminent value that we argue a carebot should promote. It is more important even than safety and social connectedness.

\section{Robots, 'presence' and the requirements of care}

Care that depends significantly on technology is already a reality in much of Western Europe, but the technology typically used is not robotic. On the contrary, some of it is decidedly low-tech. Assistive technology for older people in the UK includes wearable alarms for summoning help; smoke, $\mathrm{CO}_{2}$ and flood sensors; pillboxes that are designed to help older people to take all of their medication on time; and fall sensors. Two-way visual contact through webcams and television monitors is also available, though less widely, and relatively inexpensively. This enables family or paid support workers to 'look in' on an older person and their home without travelling (Bayer et al. 2007; Bowes and McColgan 2006). If older people are comfortable with computers, virtual visiting is cheap and easily accessed-no more difficult to obtain than a Skype account - and there are virtual visiting systems simpler than Skype which operate using local broadband networks.

What, if anything, can robots add to this array of nonrobotic assistive technology? There are a number of possible answers to this question, corresponding to differences between robots. A number of robots simulate the appearance, feel and behaviour of small domestic pets. These can have some of the beneficial effects of real pets-providing a facsimile of companionship and an outlet for a sort of affection for otherwise lonely and isolated people. ${ }^{1}$ Such robots are relatively cheap, and their therapeutic benefits are in principle available not only to older people, but to younger people who are cognitively impaired, including children with autism. Considerably more expensive are multi-functioning humanoid robots that are able to move about in an apartment or bungalow, carrying out tasks for an older person, their carers, or both. An example of such technology which we will concentrate on in what follows is the Care-O-bot ${ }^{\circledR}{ }^{2}$ Care-O-bot ${ }^{\circledR}$ platforms can be

\footnotetext{
${ }^{1}$ See for instance Paro the seal http://www.parorobots.com/index. asp.

${ }^{2}$ See http://www.care-o-bot.de/english/.
}

programmed to speak to the older person, to fetch and lift things, and to act as an audio-visual portal to the world outside the older person's home. In principle, the Care-Obot ${ }^{\circledR}$ could help to steady an older person when moving from a sitting to a standing position or as they walk. It can also be programmed to learn and to remember an older person's daily routine, remind them of things, and summon help in the event of a fall or some other recognized mishap.

In what follows, we use the term 'humanoid robot' not for a robot that simulates human behaviour, including facial expressions and posture, but for an upright multi-functioning social robot that typically has facial features, usually quite schematic or cartoon-like features, some sort of communicative interface, and perhaps arms. Care-O-bot ${ }^{\circledR}$ is such a robot. Without simulating the adult human body, it has the rough counterpart of such a body, much as a simple cartoon of a human being can be taken to resemble a human being. By 'non-humanoid' robot we will usually mean some singlefunction, often very compact, machine with no counterpart of a human body, though sometimes with the counterpart of an animal body.

Both humanoid and non-humanoid robots add to the potential benefits for older people of non-robotic assistive technology. A common benefit of some examples of both kinds of robots is that they have what we shall call 'presence'. This includes, but comes to more than, being there with the older person. Being there-in the minimal sense of being co-located with a person-is open to a mop, a broom, or a newspaper. What is meant by 'presence' is the kind of co-location of a thing with a person that brings it about that the person no longer feels alone. A child co-located with a bed will probably feel alone, even if the bed is comfortable and familiar. But a child co-located with a bed and a familiar cuddly toy will probably feel that they are in the presence of something or someone, even though the cuddly toy is inanimate and inert and has degenerated after years of handling to a lump of cloth. This illustrates what is meant by 'presence'. ${ }^{3}$ In ACCOMPANY, the Care-O-bot ${ }^{\circledR}$ has sophisticated presence, since it not only acts against the feeling of being alone, but does so by moving around with the older person, appearing to take interest in activities in which the older person is engaged, prompting him or her undertake beneficial behaviours, communicating through a touch screen and reacting to the older person's commands. This is what we mean by 'sophisticated presence'.

Evidence gathered in ACCOMPANY ${ }^{4}$ suggests that for older people exposed to it for short lengths of time in an

\footnotetext{
3 'Presence' in this sense is an effect of the robot on its companion. This is not to be confused with telepresence, where someone is not colocated with a robot, but is able to get audio-visual experience of the place where a remote robot is located, or where it is moving.

${ }^{4}$ The authors are members of the ACCOMPANY project team. The research leading to these results has received funding from the
} 
experimental smart home, Care-O-bot ${ }^{\circledR}$ has presence. Some can even imagine forming what they term 'attachment' to a Care-O-bot ${ }^{\circledR}$. Users may also give the robot gendered names. This shows that social robots are likely to be more than present to users, since attachment goes beyond not feeling alone. ACCOMPANY is adapting the Care-O-bot ${ }^{\circledR}$ for some scenarios illustrating what robot companionship for older people might mean. The scenarios call for the robot to be able to monitor the position of the user, sometimes remotely, and for fetching and carrying for the user in which the robot does not simply respond to user commands but prompts the user to do things with its aid, including moving between rooms. The ACCOMPANY robot is also in some sense a stand-in for another human presence, as it expresses a small range of emotions which aspire to make the relationship with the older person mutual and, in a straitened sense, 'empathic'. Another aspect of the robot design is that it aims to enable Care-Obot ${ }^{\circledR}$ to distinguish its user from other human beings in a home setting (e.g. visitors or members of the extended family), and to respond differentially to the user.

The ACCOMPANY design captures some aspects of companionship. Since other kinds of presence can be provided more cheaply by non humanoid social robots and by real human beings making use of non-robotic assistive technology-especially Skype technology-we are not convinced that the Care-O-bot ${ }^{\circledR}$ —especially at its current cost and with its relatively meagre capabilities-is the right form for machine-assisted care to take.

On the contrary, we think it more likely that machineassisted care will be some combination of non-robotic assistive technology and non-humanoid, social or singlefunction robots. It is true that humanoid, multi-function robots are more likely than non-humanoid, single-function robots and non-robotic technology to combine a relatively wide range of capabilities within a single, unified presence, but how important it is to combine capabilities, and how important the lifting, fetching and walk-assisting capabilities of the Care-O-bot ${ }^{\circledR}$ are, is unclear to us. It is possible that a humanoid robot has a role in assisting older people who are isolated to keep up their skills of social interaction. This is a possibility that the 'empathic' aspect of the ACCOMPANY design has tried to realize. But it is also possible that less is more in robotic technology in particular and assistive technology in general, and that a combination of different machines, some having presence and some not, may deliver more benefits.

\section{Footnote 4 continued}

[European Union's] Seventh Framework Programme (FP7/20072013) under grant agreement no. [287624]. Some ACCOMPANY deliverables (including those referred to below, are public and can be found at the project website: http://www.accompanyproject.eu/.

\section{Some comments on the ethical value of assistive technology for older people who are not cognitively impaired}

Non-robotic technology already enables people with physical disabilities, including those who are older, to live relatively independently in homes of their own. Ramps, handholds, special kinds of lighting, highly legible telephone handsets and walkers are among the kinds of equipment that might be added to a conventionally designed house to adapt it to a resident with physical disabilities (Doughty et al. 2007; Alaszewski and Cappello 2006). Then there is a variety of sensors and alarms, some designed to alert the householder to a risk, and some designed to alert a source of outside help. This equipment is characteristic of telecare. Telecare can also make use of combinations of television and webcam equipment, enabling 'virtual' visiting by health care or social workers (Dixon and Stahl 2009; Percival and Hanson 2006). Telehealth is another use of assistive technology. Here the purpose of the technology is typically to monitor a medical condition that has required or could require hospitalization, and to facilitate timely interventions if the condition worsens (Rogers et al. 2011). Unlike telehealth, telecare does not necessarily monitor vital signs or other symptoms. It monitors, often unobtrusively, how an older person is using their house, and takes unusual patterns of movement or rest, or unusual events (like water overflows in bathrooms), as cues for intervention by people outside the home.

In considering the ethical value of assistive technology, it is useful to ask whom it assists, or assists primarily. Some technology primarily assists a householder or a patient; other technology may be designed primarily to reduce the burden on carers of patients or householders. To begin with patients or householders, healthy older people are one target group for non-robotic assistive technology. Frail older people are another; older people with dementia are a third. Younger people with some cognitive impairment are a further class. ${ }^{5}$ Other technology assists family members or a care organization located at one remove from the householder or patient.

Cognitively able but physically not very capable older people are probably the central client group catered for by policy documents on telecare (Department of Health 2005, 2008, 2010). ${ }^{6}$ These are people who meet the legal standards for making decisions about their welfare, entering

\footnotetext{
5 But as ACCOMPANY is aimed at older people, this group of potential users will not be discussed here.

6 These documents tend not to distinguish between those over 65 and the much older. The 'oldest old' may pose special problems for assistive technology [see Misselhorn et al. (2013)]. The ACCOMPANY robot is not designed specifically for those in the Fourth Age, and may not be well-suited to the oldest old.
} 
into contracts, making wills and so on, but who may be much less mobile and agile than people in their 40 and $50 \mathrm{~s}$. This class is representative of the growing proportion of ageing adults in the general population of the UK and other Western countries whose health and life expectancy are much better than those of previous generations, and whose eventual demands on public care provision are as yet unknown. ${ }^{7}$ Telecare is, among other things, a way of extending the time that cognitively unimpaired and mobile older people are able to live in their own homes rather than hospital or residential care homes, publicly funded ones in particular. Those with physical and intellectual disabilities are in principle distinct from older users of telecare: although it is true that many older people suffer from dementia and physical disability, it is not clear that the ethical issues raised for telecare by the whole class of those with physically disability can readily be inferred from the ethical issues raised for telecare by older people with disabilities. What we have are overlapping groups with overlapping issues.

The decision of cognitively unimpaired but less able people to take assistive technology into their homes ${ }^{8}$ is a decision to live with a certain loss of privacy ${ }^{9}$ in return for effective emergency or care response or more effective management of long-term medical conditions. Sensors to detect falls, bed-wetting and chair-wetting, and the length

\footnotetext{
7 Though predictions for care needs based on current demand, extrapolated to the expected increase in the proportion of older people in the population, suggest something of an explosion in the need for care; e.g. OECD (2011).

${ }^{8}$ It is important to remember that all assistive technology is introduced into a person's home. The significance of its being a home and the significance of 'home' to individuals means, as we explain below, that it should only be introduced with appropriate consent from the autonomous person whose home it is.

${ }^{9}$ Users of telecare and telehealth equipment are sometimes conscious of being under surveillance and dislike the Orwellian 'Big Brother' aspects of telecare and telehealth (Percival and Hanson 2006; Robinson et al. 2007). Do these aspects count against telecare morally? Whether they do depends on whether the purpose of the monitoring is sufficiently similar to that of state security surveillance, and whether sensors are necessary for that purpose. State security surveillance seeks to collect evidence of behaviour that is illegal or damaging to the security of the state. It is not done for the benefit of the person surveilled, but for the wider public, or for the maintenance of the state. Telecare and telehealth, on the other hand, are operated for the benefit of the person monitored, and, in Western countries, are only introduced into people's homes with their consent. They are an early warning system for a health problem or a health emergency. Far from leading to arrest, prosecution and imprisonment, they trigger rescue or medical intervention for a particular person identified in advance as being medically needy. Beyond that, telecare is at least often claimed by its promoters to maintain the independence of its users (Woolham 2006). This purpose is often given greater weight, at least officially, than relieving the burden on a carer (Brownsell et al. 2003; Poole 2006; Greenhalgh et al. 2012). For a full discussion of the ethics of surveillance in telecare, see Sorell and Draper (2012).
}

of time people spend in bed or in the bathroom, are widely used. Sensors can also detect whether external doors have been opened at odd hours, or left open for an abnormally long time (Perry et al. 2009). Medical equipment that detects signs of deteriorating asthma, chronic heart and lung ailments or diabetes is now available (Garcia-Lizana and Sarria-Santamera 2007; Paré et al. 2007). Some of this equipment sends information automatically to central response centres or medical practices (Dang et al. 2009). Telehealth equipment can also send information about amounts of medication taken at different times. ${ }^{10}$

User-centred assistive technology can reduce the burden of carers, but it need not do so, especially if the user has habits that carry some risks, or has a lifestyle that is not risky but is disapproved of by family or carers. For example, if user-centred telecare facilitates private communication or visits to an older person from someone whom he or she, but not their family approves of, say a younger member of the opposite sex, whom the family suspects is only interested in obtaining the older person's money, then it might add to the worries and burdens of the carers (Draper and Sorell 2012).

This possibility notwithstanding, there are good moral reasons why user-centredness rather than carer-centredness is the appropriate default position for older people's care in general, including the design of assistive technology for them, and robot-assisted care in particular. One reason is that the older person is an adult, with a life of his or her own to lead. This point is crucial to the approach taken in this paper, which is to extend the norms of fully ablebodied, socialized adult life to older people who are frail and isolated, when there is a technology available to them that compensates for isolation and physical decline.

Why apply norms for able-bodied adults in their prime to older people? The older person is no less an adult than someone much younger whose choice of, for example, sexual or other companions would normally not be anyone else's business, not even the business of the younger person's friends or family. Likewise, a middle-aged person can form relationships that his or her family disapproves of, but their disapproval is not normally taken to be decisive for what the middle-aged person should do, even if the middle-aged person is dependent on e.g. his daughter for meals, laundry and general organization.

If the older adult is to be treated differently from the younger adult, and if that difference in treatment is to be justified morally, then there has to be something about being older that makes one less able to lead one's own life.

\footnotetext{
10 The US Food and Drugs Administration recently approved the use of an ingestible sensor in pills to monitor the medication intake of patients: http://proteusdigitalhealth.com/proteus-digital-health-announces-fdaclearance-of-ingestible-sensor/.
} 
Although there may be some facts of older-age that are relevant here-declining mobility and worsening memory, for instance-these do not mean that one is not able to make decisions about how one's life should be run. After all, many much younger people who are forgetful, or who are not very agile or mobile through some accident, are not taken to be incapable of decision-making, and the quality of their decision-making may be no better than that of an older person who has age-related forgetfulness. Unless an older person is cognitively impaired-and cognitive impairment need not attend older-age even when older people are no longer mobile-there is every reason to treat older people as all other unimpaired adults are treated, namely as able to make their own decisions, including exercising the right to make their own mistakes and take the consequences.

From a moral point of view, the decision-making of the user may even have to be allowed to extend to the question of what counts as an emergency. Under some telecare and telehealth regimes, it can be the judgment of telecare monitors that triggers an emergency intervention. Why should not people who are medically needy but perfectly competent trigger a rescue or medical intervention themselves ${ }^{11}$ This would be more consistent with the autonomy-promoting aims of assistive technology than the intervention triggered by the outsider. Some assistive technology does work in this autonomy-promoting way. Among the longest-established assistive technology devices are alarms that older people can set off if they fall or are in distress (Fisk 2003). These alarm devices can be worn, and so need never be out of reach. Alarms belong to a wider class of assistive technology devices in the control of the person receiving the care. These can include sensors for over-running baths and smoke that alert the user rather than a remote telecare hub, and that can prompt the user to set off their alarm if they feel they cannot cope. In the event that users feel that they can cope, a mishap such as a fall need not be regarded as an emergency, still less an emergency so overwhelming that outsiders need to come to the rescue.

In the same way, sensors monitoring medication use might alert healthy older users, rather than a remote carer, that tablets had not been taken. The user would then be free to take the tablets if he or she chose. Instead of outsidercontrolled assistive technology, we have here the technology of the 'smart home', that is, technology that keeps track of hazards for the householder rather than an outsider, that does not keep track of the householder him or herself,

\footnotetext{
11 We assume here responsible use of emergency facilities (see Draper and Sorell (2002)) and also note that there are anecdotal reports on older users using alarm devices because they feel lonely and regard this as one means, perhaps their only means, of getting human contact.
}

and that does not make decisions for the householder or involve others in decision-making independently of the householder. It is smart home technology along these lines that should probably be preferred to outsider-controlled technology in the care of the competent but capable elderly, as it better respects their autonomy. ${ }^{12}$

User control can sometimes be the other side of the coin of user isolation. The older householder who autonomously manages her life, whether or not she has a chronic illness, may often do so because she is alone. Assistive technology sometimes reduces regular human contact, in particular visits of, or to, care assistants and other carers (Clark et al. 2007; Lim et al. 2007). Whether telecare must increase isolation in order to serve its standard twin purposes of promoting independence and reducing the public expenditure involved in hospitalization or maintaining state-run care homes is not always easy to determine (Sorell and Draper 2012; Murray et al. 2011; Pols 2010). ${ }^{13}$ Relatively inexpensive virtual visiting can make available important facets of human contact. Contact can even be enhanced, since technology reduces the size of the obstacle posed by distance and the familiar problem of having to be in two places at once. When one visits virtually, with good, real time audio/visual access to the older person's home, the virtual visitor is in two places at once, for most purposes. Similarly for the older people visited. The equipment enables older people who are virtually visited to see not only the people they are conversing with but their home environments in real-time. Earphones can even make virtual visitors much more audible for the hard of hearing than being co-present with the same people in a room with a great deal of background noise. ${ }^{14}$ It is true that equipment for virtual visiting also creates opportunities for intrusion-but this may be no greater than home visiting. When it is user-controlled and combined with the usual array of sensors and monitors, however, it may at least in principle provide health and social

\footnotetext{
12 Locating control with the user fits in with one finding from surveys of users of telecare, namely that they dislike the way it takes away their control over revealing increasing frailty or disability (Sorell and Draper 2012). This desire to retain control was also reflected in the data collected by MADoPA and reported in ACCOMPANY deliverable D1.2 Report on user and system requirements and first outline of system functionality.

${ }^{13}$ It is also possible the developments in technology and human interactions with technology will change the meaning of isolation. People who, even when young, maintain social relations online may feel far less lonely when they lose physical mobility than older people for whom computer contact by itself does not relieve feelings of isolation. In the same way, playing with a robot dog might well come to feel just as satisfying for future older people as playing with a real dog might today. For more on the way that the evolving use of technology can reconstitute such concepts as isolation, see Coeckelbergh (2012)

14 There is considerable literature on tele-consultation and within this, evidence that focussing on a single item can improve concentration, see for instance Sävenstedt et al (2005)
} 
gains for older people, cost-savings for health and social services, and a more manageable care burden for friends and family living separately from users.

\section{Carebots versus low tech assistive technology}

What do robots actually add, and what can they potentially add, to non-robotic assistive technology? What in particular can the Care-O-bot ${ }^{\circledR}$ in ACCOMPANY add? ACCOMPANY is user- centred rather than carer-centred. Its robot has not been conceptualized as a piece of technology that helps the older person's family or care providers by being their representative in the older person's house, doing for the older person what the family or carers would otherwise do, and allowing carers more time of their own. Instead, it has been designed to serve as a multi-functioning, humanoid presence in an older person's home, capable of acting as companion, helper and enabler, and sensitive to the wishes of the user before the wishes of others.

Multi-functioning, humanoid robot companions are at one end of a spectrum of robotic products with care or enablement functions. ${ }^{15}$ At the companion end of the robotic spectrum can also be found non-humanoid companion devices such as dolls and simulations of small animals. There are also hybrids of humanoid robots and companion animals. Riken have developed the Riba robot (Robot for Interactive Body Assistance): an adult-sized robot designed to look like a streamlined white teddy bear that can pick up and carry humans from a bed to a wheelchair. ${ }^{16}$ At the other end of the spectrum are devices that are more like clothing, and, when worn, markedly increase the strength of users. ${ }^{17}$ In between are robotic devices $^{18}$ whose functions, including monitoring and functioning as an interactive portal, are carried out separately by different kinds of telecare devices. Other robots are single function machines that enable the user to be more independent, such as My Spoon ${ }^{19}$ and vacuuming and floor-washing robots. ${ }^{20}$

\footnotetext{
15 ACCOMPANY deliverable D1.1 Status of elderly care in Europe and the potential for service robots. Available http://accompanypro ject.eu/ [Accessed 19/1/2014].

$16 \mathrm{http} / / / \mathrm{rtc}$.nagoya.riken.jp/RIBA/index-e.html.

${ }^{17}$ For a video of the Cyberdene HAL "power suit", see http://www. youtube.com/watch?v=fy7ipDAyXtI\&feature=related.

18 These are the so-called "Remote Presence" robots manufactured by intouch. See http://www.intouchhealth.com/products-and-services/ products/rp-7i-robot/

19 My Spoon helps users to feed themselves. http://www.secom.co.jp/ english/myspoon/usage.html

${ }^{20}$ Such as those produced by iRobot http://www.irobot.com/uk/ home.aspx.
}

The literature on the ethics of robotics sometimes identifies tensions between the design and use of carebots-including some that are similar to the Care-O-bot ${ }^{\circledR}$ used in ACCOMPANY - and the morally desirable treatment of older persons as autonomous adults. Vallor (2011) has identified the following concerns from her review of the literature:

1. The objectification of the elderly as "problems" to be solved by technological means (Sparrow and Sparrow 2006; Sharkey and Sharkey 2010)

2. The potential for carebots to either enhance or restrict the capabilities, freedom, autonomy, and/or dignity of cared-fors (Borenstein and Pearson 2010; Sharkey and Sharkey 2010; Decker 2008)

3. The potential of carebots to enhance or reduce engagement of cared-fors with their surroundings (Borenstein and Pearson 2010; Sharkey and Sharkey 2010)

4. The potential of carebots to enhance or intrude upon the privacy of cared-fors (Sharkey and Sharkey 2010)

5. The quality of physical and psychological care robots can realistically be expected to supply (Coeckelbergh 2010; Sparrow and Sparrow 2006)

6. The potential of carebots to either reduce or enhance cared-fors' levels of human contact with families and other human caregivers (Sparrow and Sparrow 2006)

7. The potential of carebot relations to be inherently deceptive or infantilizing (Sparrow and Sparrow 2006; Sharkey and Sharkey 2010; Turkle 2006)

The second of these seven concerns is the one that ACCOMPANY principally tries to address. Far from restricting the capabilities, freedom, autonomy and dignity of users, ACCOMPANY aims at maximizing those things. We shall first explain how ACCOMPANY sets out to enhance or at least preserve the autonomy and capabilities

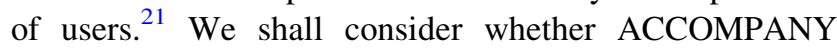
addresses other issues on Vallor's list. Finally, we shall return to the question of whether the ACCOMPANY Care-

\footnotetext{
21 'Capabilities' is used here in its ordinary sense, as a synonym for 'abilities', and not in the senses assigned to the term by Sen, and Sen and Nussbaum, in their work on the capability approach to development. Although we realize that this approach (primarily in the Nussbaum version) has been extended to robots (Coeckelbergh 2012), we think that it is ill-suited to different stages of the life course, in particular older age. In Nussbaum's hands, the capability approach is essentially a repackaging of Aristotle, which is in its turn ill-suited to questions about the flourishing of human beings with disabilities and the possibility of flourishing at stages of life in which there is a natural decline in capacities. A proper discussion of these issues is beyond the scope of the paper, but an important point would be that flourishing for a species (central to Aristotle) questionbeggingly privileges certain points in the life course of members of that species.
} 
O-bot ${ }^{\circledR}$ and carebots generally do better than lower tech solutions in assistive technology.

The ACCOMPANY Care-O-bot ${ }^{\circledR}$ is designed to be stationed in the home of the older person. It is not brought into the older person's home only from time to time. Nor does it divide its time between a number of different rooms in an institutional care-home corridor. Instead, it is a semipermanent fixture in a home occupied by one person. Its role in that person's home is partly that of helper, partly that of enabler, partly that of co-learner, and partly that of companion.

The Care-O-bot ${ }^{\circledR}$ is able to lift and carry household objects, and also to fetch objects at the command of the user. It is also able to remind the user of different scheduled or routine events, such as a visit, or the need to place a shopping order, or to go to a doctor's appointment. The robot is able to keep track of the user's position in the house and to register falls or other signs of harmful incidents. It is able to distinguish the user from other people who might enter the home, and it is able to treat the orders or requests of the user as having more authority than those of visitors. The co-learner role is a matter of the process by which the robot and the user accommodate themselves to one another. The user's routine will shape many interactions between the user and the robot. For example, if the user often wakes at 9 am rather than 7 a.m., the robot can learn that and be ready to fetch a morning drink at the right time. If a routine-disrupting appointment is made, the robot can register that and prompt the user to get dressed for a visit or to go out at a certain time. The robot can also take part in recreational pastimes-providing music to go with a song, or perhaps staying in the same room as the user as he or she watches television, and making gestures which suggest it is giving attention to the user or what the user is doing. Through its tray/tablet it can offer a video and internet portal, making possible virtual visiting.

Although the Care-O-bot ${ }^{\circledR}$ is in most respects at the service of its older user, the Siena roboticists in the ACCOMPANY consortium are seeking to endow it with capabilities that contribute to maintaining the social skills of the user-by making the obedience of the robot less than absolute. Sometimes the 'displeasure' of the robot is communicated to the user through a tablet interface showing a diagrammatic "empathic mask" (Stienstra and Marti 2012). This empathic mask can signal the robot's 'worry' about the older person, its 'pleasure' at his or her co-operation or 'displeasure' when he or she is overinsistent or impatient. The effect of this is to remind a user who may be interacting socially mainly with the robot that it, as the local representative of the social world, needs to be treated with a kind of consideration, and that the social skills of responding to gentleness with gentleness need to be kept up. The Siena work also makes possible a high degree of sensitivity to tactile interactions between the user and the robot. The tablet interface between the user and the robot can register the pressure exerted on it when the user squeezes it, and can process a hard squeeze as an indication of urgency in a command. Again, the robot can simulate 'emotional synchronization' with the user, apparently taking up a position near the user and directing its attention where the user does when, for example, the user watches television.

In what ways does the Care-O-bot ${ }^{\circledR}$ promote the autonomy and independence of the older person? To begin with, the Care-O-bot ${ }^{\circledR}$ takes the user's routine and the preferences embodied in this routine as its frame of reference. This means that the user's choices are foremost and, other things being equal, are implemented unquestioningly. So the agent's autonomy is not at all impaired. It would be impaired if the choices of others started to supplant the user's choices. But in ACCOMPANY scenarios this does not happen. Far from introducing new choices, still less choices at variance with those of the user, the Care-O-bot ${ }^{\circledR}$ takes its cue from the user's choices. The robot is also able to co-ordinate those choices through scheduling and prompting abilities. In both of these ways the ACCOMPANY Care-O-bot ${ }^{\circledR}$ promotes the autonomy of the user.

User safety constrains the autonomy-respecting features of carebots. Sharkey and Sharkey (2010) ask what would happen if a user instructed a lifting and carrying robot to release him or her over the side of a high balcony in an apartment building. Even if that suicidal request were competent and highly autonomous-not the result of treatable depression, for example- there would be a good moral reason for programming a carebot not to comply with it, namely that the robot would not normally be able to tell whether such a request was competent and autonomous. Likewise, one would expect a carebot with monitoring abilities to abort an activity requested by the user if, while undertaking that activity, it registered that the user had fallen or that his or her vital signs had suddenly changed. But notice that we would expect the same behaviour of an autonomy-respecting human helper as well, since loss of life and sudden medical emergencies disrupt or undermine the exercise of autonomy.

Autonomy-choosing for oneself and acting in accordance with one's choices-is different from independence. Independence is being able to act on one's choices without depending on the consent or co-operation or resources of others. If someone chooses to live the life of a sailor, for example, but can only succeed in doing so if a shipping company offers employment, then there is a clear sense in which the agent is not an independent sailor, however much his choice of sailing as an occupation is autonomous. Independence might only be achieved if he owned a suitable boat or ship for as long as he wanted to live the life of 
a sailor. In the case of older people, autonomy can sometimes co-exist more or less constantly with dependence rather than independence. In other words, the choices of older people can often need to be realized through the efforts of others.

Although an older person can still make his or her own choices, he or she may not be physically strong enough, or mobile enough, or rich enough to see them through. Carebots can act against some sources of dependence, like physical weakness, but not others, such as lack of wealth. ${ }^{22}$ Sometimes in discussions about older people, independence is not understood with respect to one's command of the means for realizing choices in general, but rather in terms of one's ability to keep oneself clean, fed, sheltered, unharmed and legally occupied without the constant assistance of other people. Carebots readily promote independence in this limited sense, but not independence in all of the respects in which it affects autonomous choices.

Carebots in general and the ACCOMPANY Care-Obot ${ }^{\circledR}$ in particular also address issues other than autonomy and independence on Vallor's list. The sixth concern ('The potential of carebots to either reduce or enhance cared-fors' levels of human contact with families and other human caregivers') highlights the potential isolation of older people whose main interactions are with machines. We have already seen that, in telecare, technology can be a gateway rather than a barrier to human contact. This is because it can act as a portal for two-way communication and more. What about carebots? Although they also afford the possibility of virtual visits, there is a clear difference between having a two-way television in one's house and having a Care-O-bot ${ }^{\circledR}$. The Care-O-bot ${ }^{\circledR}$ is a presence in its own right in a way a television is not. To put it in another way, the television is not a subject of interaction but at most a medium of interaction. On the other hand, a Care-Obot $^{\circledR}$ is a subject of interaction-a possible 'conversation' partner and a possible participant in synchronised activity.

Admittedly, the Care-O-bot ${ }^{\circledR}$, s current communicative abilities are so limited as to be conversational only in an inverted commas sense; admittedly, the extent to which its presence fills a gap left by human contact is very restricted. Still, there is a sense in which the Care-O-bot ${ }^{\circledR}$ in ACCOMPANY and other carebots fulfil the conditions for what, at the beginning of this paper, we called 'presence': when carebots are co-present with people, those people can feel that they are not alone. This does not seem to be a power of television sets. It is of course possible for an

\footnotetext{
22 ACCOMPANY deliverable D1.1 'Status of elderly care in Europe and the potential for service robots' noted that there are inconsistencies across the EU in how assistive technologies for older people may be funded, and not all EU citizens in need of help can be sure of receiving state funded assistance. Available http://accompanyproject. eu/ [Accessed 19/1/2014].
}

image on a two-way television to produce the feeling of not being alone. But a Care-O-bot ${ }^{\circledR}$ resident in one's home can create this feeling even when it is not functioning as a virtual visiting portal. This is an important difference between non-robotic assistive technology and robots.

Can only a carebot-typically an adult-sized humanoid fetcher-carrier-lifter with restricted communicative capacities-have presence, or is presence open to much simpler robots? Much simpler non-humanoid social robots undoubtedly can have presence. The Paro ${ }^{23}$ - a small furcovered robot that looks like a seal-is specifically designed for therapeutic uses with older people. It is programmed to exhibit a range of responses to being petted, including moving its tail and opening and closing its eyes. It also 'learns' actions that the user likes or dislikes (it responds to being hit as well as petted), can respond to voice direction and tone, and detects the difference between day and night and is more or less active accordingly. Although the evidence regarding Paro's actual effectiveness as a companion is open to more than one interpretation, some studies have concluded that animal robots have some of the therapeutic powers of real domestic animals, ${ }^{24}$ but without the care-burdens of owning a real domestic animal. Again, it is plausible that Paro serves the purposes of the oldest old better than the somewhat younger intended users of the ACCOMPANY carebot.

If the isolation and loneliness of older people were the only or the main problem that robots were being introduced to solve, then, a multi-functioning humanoid robot might not be needed. And there would be lower-tech solutions to the loneliness problem if there were regular two-way virtual visiting between actual human beings. Or a combination of simpler robots and two-way television may be the best of both the high-tech and low-tech worlds for combating loneliness, providing both permanent and lowmaintenance presence but also regular human contact. (No tech visits would of course be possible and might be best of all therapeutically, but could be expensive in time and money).

\section{An ethical framework for judging carebots for older people}

When what is in question is the promotion of autonomy, independence and some form of human contact, what, if anything, recommends a carebot solution to providing care for older people over a telecare, or single-function and simple companion robot solution, or a combination of

\footnotetext{
${ }^{23} \mathrm{http}: / /$ www.parorobots.com/index.asp

${ }^{24}$ See Misselhorn et al. op. cit.
} 
telecare and single-function and simple companion robots? If the money cost of a multi-function, humanoid carebot is taken into account, the answer may be "Nothing". On the other hand, if financial costs are disregarded, then the answer on the basis of the previous discussion may be that the carebot solution delivers physical help, and the ability in principle to integrate telecare and sophisticated presence. By 'sophisticated presence', as explained in the section "Robots, 'presence' and the requirements of care", we mean that the carebot interacts and can even initiate interaction with the user. Moreover, the quality of interaction is far more sensitive and far more challenging than the passive twitches and facial expressions of Paro. By taking over some of the functions of telecare, the ACCOMPANY Care-O-bot $\left.{ }^{(}\right)$can keep track of the location and condition of the user. It does so, however, from close at hand, potentially enabling quicker intervention or emergency response than conventional telecare devices relaying data to a remote information hub (assuming that the carebot is not itself programmed to summon help from a similar hub). In other words, cost considerations apart, a carebot may give us in a single package a highly desirable embodiment of assistive technology alongside practical help with lifting, carrying and fetching.

The previous discussion, however, may be inadequate for a full answer to the question of the comparative value of low-tech and robotic assistive technology. So far we have been guided by a list of ethical issues raised by philosophers and technologists who have reflected on the capabilities of robots designed or used to provide care for older people and meet the needs of older people as they present themselves in ordinary experience. But perhaps the common sense of philosophers and technologists is a bad guide to the needs or preferences of the elderly. The preferences and needs of the current population of older people are not representative of future older people, and are subject to cultural variation even in the present. Moreover the list of ethical issues depends on the assumption that the experience of older people, especially in the West, is more or less uniform (Parks 2010). ${ }^{25}$

Any development of an ethical framework for evaluation of carebots must be informed by the attitudes of older people themselves, with allowances being made for big variations in technophobia between people who currently

\footnotetext{
25 Jennifer Parks, for instance, notes that cultural difference may be significant in terms of both how people respond to robots versus humans and different robotic persona. Discussion about the paucity of data about, and understanding of, cultural differences in perceptions and approaches to ageing in general can be found in University of Birmingham Policy Commission 2014 'Health Ageing in the 21st Century: the best is yet to come.' Available http://www.birmingham. ac.uk/research/impact/policy-commissions/healthy-ageing/index.aspx [Accessed 6/3/2014].
}

are 60 years old and people who are currently over 80 years of age. The importance to an ethical framework of taking into account user-attitudes is connected with the value of autonomy. If carebot use is to take its cue from the wishes of individual older users of carebots, and if surveys of older people reveal a range of design-relevant preferences which do not correlate with the design features of the carebot that engineers intend to realize (Van der Plas et al. 2010), this may suggest that engineers think they know better than their potential older users what carebots should be like, or that they do not know and have not bothered to find out what older users of carebots might be looking for. Either way, the potential of the engineer-designed carebot to promote the autonomy of older users might be compromised.

ACCOMPANY has conducted research among panels of older people in the UK, the Netherlands and France. The project is investigating what users might want from a carebot, and has found that mobility, self-care and isolation are major preoccupations, while co-learning seems not to be. ${ }^{26}$ Does this finding mean that ACCOMPANY should drop co-learning from its designs for robots? Not necessarily. Co-learning may have other effects that older people could benefit from and that they want, even if they want other effects more. There could be a therapeutic rationale for some design features that older people don't want or don't want much, so long as on balance groups of older people have been consulted and listened to in relation to design, and so long as the ACCOMPANY Care-O-bot ${ }^{\circledR}$ accommodates itself to individual users rather than coming up with an agenda of its own. To go back to Siena's methods of keeping up older people's social skills by adjusting its behaviour to the user's tone of voice, this might have what is broadly speaking a therapeutic benefit even if the older person doesn't like it much.

Vallor's list of ethical concerns indeed anticipates the way that the Siena design might be justified. It in effect asks philosophers and technologists to think about:

3.The potential of carebots to enhance or reduce engagement of cared-fors with their surroundings

and

5. The quality of physical and psychological care that robots can realistically be expected to supply.

The Siena innovations try to improve social skills and, indirectly, the psychological well-being of older users. They also introduce companionship into such routine ways

\footnotetext{
${ }^{26}$ See ACCOMPANY deliverables D1.1 Status of elderly care in Europe and the potential for service robots and D1.2 Report on user and system requirements and first outline of system functionality. Both available http://accompanyproject.eu/ [Accessed 19/1/2014].
} 
of engaging with one's surroundings such as watching television and helping with such tasks as moving objects from one room to another, which promotes living in orderly and clean surroundings.

Even when the attitudes of users are taken into account, there may be conflicts within the range of ethical values that are individually relevant to providing care for older people. We have already seen that autonomy can conflict with safety: a carebot that is otherwise dedicated to fulfilling the wishes of its older user ought not to comply with a request that is suicidal. Similarly, although older autonomous people have a right to privacy at least as extensive as that of younger people, there may be occasions when a carebot should report a fall to a non-resident carer or a medical assistance hub, even if that is against the wishes of the older person himself or herself.

Against this background, what sort of ethical framework should be proposed for the design of carebots. The framework must identify and define values that should be promoted or at least respected by carebot design and use in relation to older people, and it must say which value is, or which values are, overriding when there is a conflict. The ACCOMPANY project addresses isolation and declining physical capacity in older people who continue to live and want to live in their own homes. If a robotic companion is to be a solution, its design must promote the following:

- autonomy-being able to set goals in life and choose means;

- independence-being able to implement one's goals without the permission, assistance or material resources of others;

- enablement-having or having access to means of realizing goals and choices;

- safety-being able readily to avoid pain or harm;

- privacy-being able to pursue and realize one's goals and implement one's choices unobserved;

- social connectedness-having regular contact with friends and loved ones, and safe access to strangers one can choose to meet.

All of these values lie in the background of most ablebodied, independent adult life, and our approach is to extend these values to later life unless there are reasons not to do so. Isolation and physical decline might be thought to be such reasons-unless a technology can compensate for them. The ACCOMPANY scenarios animate these reasons. And a particular design of robot companion compensates for them.

It is, however, inevitable that circumstances will arise where these values are in tension. When this happens one value is likely to be given priority over another. The preceding discussion has suggested that autonomy is a crucial value but that it can be outweighed when respecting it would threaten a user's life or physical well-being. It might be thought to follow, then, that of the six values, safety is supreme, trumping even autonomy.

This seems to be a mistake. Not every threat to safety, even when realized, produces major injury. When the worst that the exercise of autonomy produces is minor harm, or not-so-minor but tolerable and survivable harm, autonomy might win out over safety. Admittedly, the meaning of 'major harm' and 'minor harm' varies over a life-course. Falls that are tolerable at 45 years of age and classifiable as minor then would not be classifiable as minor at 90 , but the threshold has to be quite high if the older person's autonomy is not to be in danger of being entirely undermined by too conservative a safety regime. In other words, autonomy, not safety, should normally be the ruling value in carebot design. For example, if an older person prefers being bruised for a week to staying seated or using a walker, not interfering with a decision to get up and be active seems to be consistent with the discretion usually allowed to middle-aged and younger adults with respect to their health and safety, even when minor harm results. Allowing the older person the same discretion might mean designing a carebot so that its prompts to use a walking frame etc. can be disabled (and perhaps later re-enabled) by the user.

Because privacy promotes autonomy by allowing users to discover when unobserved what their limits or vulnerabilities are, and to factor those into their plans, carebots should not normally be able to report information about users to outsiders or let anyone into an older person's home without permission. On the other hand, acting on some kinds of information without reporting to outsiders might be valuable. Thus, if the carebot has or is connected to flood sensors in a smart home, there is no reason why it or the smart home technology cannot trigger a cut in the water supply and then ask the user what they next want done. This is in keeping with autonomy. Cutting the water supply and asking an outsider for subsequent instructions would undermine user autonomy unless the user was incapacitated.

Social connectedness is desirable, other things being equal, because of its potential benefits to physical and mental health. But the 'other things being equal' is important: it is possible for social connectedness to empower busybodies, without any benefit to the user. Instead of social connectedness full stop, chosen social connectedness with chosen people seems desirable, with the user deciding, as most adults routinely do, whom to include and whom not to include in their social circle. A user who disliked all eligible social connections might intelligibly choose isolation, but, given the reach of social networks afforded by the World Wide Web, the number of eligible social connections is likely to be much larger than 
the number of people the user has good reasons or any reasons for shunning.

Enablement might also be in tension with autonomy, since enablement may require individuals to do things for themselves that they might prefer were done for them, or that they might prefer not to do at all. Robotic devices are being developed to help with physical rehabilitation following stroke, accident or amputation. Physiotherapy of this kind often requires patients to be coaxed, persuaded and even paternalistically coerced into repeating movements by physiotherapists, who may themselves move or position the patients in ways that although initially uncomfortable are necessary for rehabilitation. Returning someone to a state of greater independence is certainly compatible with autonomy; the question is whether it is compatible with autonomy for a carebot to coerce someone to adhere to regimes that will return them to greater independence.

The answer to this question may lie in what is agreed with the older person at the time a rehabilitation device or robot with enabling capabilities is placed with that person's consent in their home. In the case of single-purpose device, there would be no objections to removing a state-funded device that was lying unused or not being used properly. Carebots pose a different challenge because they are designed to be multi-functioning and these other functions would also be lost if they were removed. Enablement functions are not quite the same as those providing potential social interaction. Disliking social interaction and preferring isolation is a matter of taste. Working against a carebot programmed to maintain independence is not simply an expression of taste, but a kind of resistance to independence. Again, the robot and its developers would not necessarily be working against the autonomy of older users if the robot refused to do things that the older person could reasonably do for herself, or which it might be good for her to do for herself. Indeed, we can envisage something of a spectrum of mutual accommodation. At one extreme might be a user's refusal to cooperate with the robot in maintaining his or her mobility. At the other extreme might be automatic robot compliance with all user requests, even the request to be thrown off the balcony. Between the extremes might be cases where the robot enables the user to eat, or drink or smoke excessively. In this respect choices about the programming of carebots reflect the ethical issues raised more generally in health promotion and public health, where what people want is not necessary what is good for them, and satisfying their desires can be in tension with health interests.

One of the challenges for the ethical framework in ACCOMPANY is that the Care-O-bot ${ }^{\circledR}$ can play a variety of roles (companion, helper and enabler), each of which is subject to different norms in human-to-human service provision.
To take companionship first, we can assume that the Care-O-bot ${ }^{\circledR}$ is not designed to simulate a family member but rather to counteract the experience of being always or mostly alone. The Care-O-bot ${ }^{\circledR}$ might therefore play a role similar to that of a paid companion in late eighteenth and early nineteenth century England. The companion was paid to provide constant company, usually for single people, and shared their employer's home. This was a role that struck a balance between friend and servant. The companion could be a confidante, but, unlike the friend, was an employee who had very little autonomy and could be called upon to help with 'light' duties—-such as sewing or playing sport. As in the case of the Care-O-bot ${ }^{\circledR}$, the relationship was one-sided, with the feelings, wishes and whims of the employer (or older user in the Care-O-bot ${ }^{\circledR}$ case) having most of the weight and those of the companion having little or none. However, it was considered unseemly to be unduly rude to or rough with the companion-which corresponds with the concerns for 'respectful' interaction being worked on in by the Siena partner in ACCOMPANY.

A helper may be a servant, professional or volunteer, and these three roles will now be considered in turn. Servants are paid to do their employer's bidding, usually without question. As it operates in ACCOMPANY, CareO-bot ${ }^{\circledR}$ does not quite take on the traditional role of the servant, because it is intended to perform tasks that users are physically unable, rather than unwilling, to do for themselves. On the other hand, to place Care-O-bot ${ }^{\circledR}$ in the servant role suggests, appropriately enough, that the older user is controlling the robot rather than the robot controlling the older user. It also suggests that the robot should be discreet, keeping household matters private.

To the extent that it is designed for the frail and those with physical impairments, the Care-O-bot ${ }^{\circledR}$ could be associated with caring roles filled by nurses, healthcare assistants and doctors, especially when they are equipped with interfaces for telehealth interventions. Human carers are not necessarily obedient servants. On the contrary, they are likely to have their own ideas about how much help to give and when, what constitutes help and what form it should take from occasion to occasion. So there may be a tension between placing Care-O-bot ${ }^{\circledR}$ in the caring role and placing it in a servant role. In one the older person is the boss, and in the other the older person sometimes needs to accommodate the carer. Informal, voluntary care such as that which might be provided by a friend, incorporates both the care element and that of companionship. It reinforces the idea that that whilst the robot is present at the invitation of the older user, it should not be exploited or ordered about. It is also more of a relationship between equals, even though the older user retains the upper hand and the robot has only limited capacity to withdraw from unsympathetic behaviour or tone. 
'Enabler' may suggest superiority over the enabled: the human enabler is the one with the knowledge, skills, abilities and powers to enable. This may also raise questions about who is deferred to when older person and their enabler are in conflict. There is a corresponding tension between enablement and autonomy.

When autonomy conflicts with other values that govern the possible roles of Care-O-bot ${ }^{\circledR}$, which should prevail? A way of summarizing much of the foregoing is by saying that autonomy should. Autonomy can make sense as the organizing value of the ethical framework for the design of carebots. Being the organizing value, autonomy also constrains additions to the value framework: other potential values would be consistent with autonomy or else have some independent moral grounding. Should further values be added to those already introduced?

One source of further values is the interests of carers connected to the older person. Carers enter the ethical framework developed so far through its values of safety and social connectedness, in turn constrained by the value of keeping the older person autonomous for as long as possible. This may not be the right way for carers to enter the framework. It might be thought that by putting older people and their choices at the centre of things, the framework denies the dependence of older people on carers and is in any case too individualistic. For example, the framework recognises threats to the autonomy of older people from carers but not the sheer hard work and sometimes sacrifice of their carers. Perhaps the framework needs to reduce the value of autonomy in interactions with the older person the more other people have their choices reduced by their caring role. Concretely, this might mean that the ability of the older person to judge and take risks that could lead to injury and greater dependence might be restricted the more dependent they are on others. It might also justify more monitoring and more reporting to carers.

We are not persuaded that autonomous older persons necessarily overburden carers, even when they are dependent. But it helps to remind ourselves that we are not concerned with the general question of the best way of being fair to carers. We are only concerned with the way that carers' interests should be represented in a framework for the design of carebots. Since carebots of the kind being developed in the ACCOMPANY project assume only moderate physical disability and near complete cognitive functioning in the older people who would be living with the Care-O-bot ${ }^{\circledR}$, the question of trade-offs between autonomy and high dependence does not arise. That does not mean that there are no difficult questions about what carers have a right to know about in the lives of older people and what decisions of older people they have a right to veto, but in general the burden of proof will be on carers rather than the other way round. ${ }^{27}$

Acknowledgments The work in this paper was partially funded by the European project ACCOMPANY (Acceptable robotics COMPanions for AgeiNgYears). Grant agreement no.: 287624.

Open Access This article is distributed under the terms of the Creative Commons Attribution License which permits any use, distribution, and reproduction in any medium, provided the original author(s) and the source are credited.

\section{References}

Alaszewski, A., \& Cappello, R. (2006). Piloting telecare in Kent County council: The key lessons. Final report. Canterbury: University of Kent, Centre for Health Services Studies.

Bayer, S., Barlow, J., \& Curry, R. (2007). Assessing the impact of a care innovation: Telecare. System Dynamics Review, 23(1), 61-80.

Borenstein, J., \& Pearson, Y. (2010). Robotic caregivers: Harbingers of expanded freedom for all?'. Ethics and Information Technology, 12(3), 277-288.

Bowes, A., \& McColgan, G. (2006). Smart technology and community care for older people: innovation in West Lothian, Scotland. Edinburgh: Age Concern Scotland.

Brownsell, S., Bradley, D., \& Porteous, J. (2003). Assistive technology and telecare: Forging solutions for independent living. Bristol: The Policy Press.

Clark, R. A., Inglis, S. C., McAlister, F. A., et al. (2007). Telemonitoring or structured telephone support programmes for patients with chronic heart failure: Systematic review and meta-analysis. British Medical Journal, 333, 942.

Coeckelbergh, M. (2010). Personal robots, appearance and human good: A methodological reflection on robots. International Journal of Social Robots, 1(3), 217-221.

Coeckelbergh, M. (2012). How I learned to love the robot: Capabilities, information technology and elderly care. In I. Oosterlaken \& J. van den Hoven (Eds.), The capabilities approach, technology and design (pp. 77-85). Dordrecht: Springer.

Dang, S., Dimmick, S., \& Kelkar, G. (2009). Evaluating the evidence base for the use of home telehealth remote monitoring in elderly with heart failure. Telemedicine and e-Health, 15(8), 783-796.

Decker, M. (2008). Caring robots and ethical reflection: The perspective of interdisciplinary technology assessment. $A I$ \& SOCIETY, 22(3), 315-330.

Department of Health. (2005). Building telecare in England. London: Crown.

Department of Health. (2008). High quality care for all: NHS Next stage review. London: Crown.

Department of Health. (2010). Building the National Care Service. London: Crown.

Dixon, R. F., \& Stahl, J. E. (2009). A randomized trial of virtual visits in a general medicine practice. Journal of Telemedicine and Telecare, 15(3), 115-117.

\footnotetext{
27 A further and extremely important consideration is monetary cost. Until the price of Care-O-bot ${ }^{\circledR}$ is much lower than it is now, the presumption in favour of lower tech and cheap assistive technology must remain strong.
} 
Doughty, K., Monk, A., Bayliss, C., et al. (2007). Telecare, telehealth and assistive technologies-do we know what we're talking about? Journal of Assistive Technologies, 1(2), 6-10.

Draper, H., \& Sorell, T. (2002). Patients' responsibilities in medical ethics. Bioethics, 16(4), 335-353.

Draper, H. \& Sorell, T. (2012). 'Telecare and Care' Bioethics 16th April. doi:10.1111/j.1467-8519.2012.01961.x.

Fisk, M. (2003). Social alarms to telecare: Older people's services in transitions. Bristol: The Policy Press.

Garćia-Lizana, F., \& Sarrĩa-Santamera, A. (2007). New technologies for chronic disease management and control: A systematic review. Journal of Telemedicine and Telecare, 13, 62-68.

Greenhalgh, T., Procter, R., Wherton, J., et al. (2012). The organising vision for telehealth and telecare: Discourse analysis. BMJ Open, 2, $\mathrm{e} 001574$.

Lim, F. S., Foo, M., Kanagalingam, D., et al. (2007). Enhancing chronic disease management through telecare-the Singapore Health Services Experience. Journal of Telemedicine and Telecare, 13(Suppl. 3), 73-75.

Misselhorn, C., Pompe, U., \& Stapelton, M. (2013). Ethical considerations regarding the use of social robots in the fourth age. The Journal of Gerontopsychology and Geriatric Psychiatry, 26(2), 121-133.

Murray, E. et al. (2011). Why is it difficult to implement e-health initiatives? A qualitative study. Implementation Science, 6(6), $1-11$.

OECD (2011). Health at a Glance 2011: OECD Indicators. OECD Publishing. http://dx.doi.org/10.1787/health_glance-2011-en.

Paré, G., Jaana, M., \& Sicotte, C. (2007). Systematic review of home telemonitoring for chronic diseases: The evidence base. Journal of the American Medical Informatics Association, 14(3), 269-277.

Parks, J. (2010). Lifting the burden of women's care work: Should robots replace the "human touch"? Hypatia, 25(1), 100-120.

Percival, J., \& Hanson, J. (2006). Big brother or brave new world? Telecare and its Implications for older people's independence and social inclusion. Critical Social Policy, 26, 888-909. see esp. p. 898.

Perry, J., Beyer, S., \& Holm, S. (2009). Assistive technology, telecare and people with intellectual disabilities: Ethical considerations. Journal of Medical Ethics, 35, 81-86.
Pols, J. (2010). The heart of the matter: About good nursing and telecare. Health Care Analysis, 18(4), 374-388.

Poole, T. (2006). Wanless social care review: Telecare and older people. London: The King's Fund.

Robinson, L., et al. (2007). Balancing rights and risks: Conflicting perspectives in the management of wandering in dementia. Health, Risk and Society, 9, 389-406.

Rogers, A., et al. (2011). Established users and the making of telecare work in long-term condition management: Implications for health policy. Social Science and Medicine, 72, 1077-1084.

Sävenstedt, S., Zingmark, K., Hydén, L.-C., \& Brulin, C. (2005). Establishing joint attention in remote talks with the elderly about health: A study of nurses' conversation with elderly persons in teleconsultations. Scandinavian Journal of Caring Sciences, 19, 317-324.

Sharkey, A., \& Sharkey, N. (2010). Granny and the robots: Ethical issues in robotic care for the elderly. Ethics and Information Technology,. doi:10.1007/s10676-010-9234-6.

Sorell, T., \& Draper, H. (2012). Telecare, surveillance and the welfare state. The American Journal of Bioethics, 12(9), 36-44.

Sparrow, R., \& Sparrow, L. (2006). In the hands of machines? The future of aged care. Minds and Machines, 16(2), 141-161.

Stienstra, J., \& Marti, P. (2012). Squeeze me: gently please. Paper presented to NordiCHI 2012 conference in October 2012.

Turkle, S. (2006) A nascent robotics culture: new complexities for companionship. AAAI Technology Report Series Available online http://web.mit.edu/sturkle/www/pdfsforstwebpage/ST Nascent\%20Robotics\%20Culture.pdf accessed 5.9.2012.

Vallor, S. (2011). Carebots and caregivers: Sustaining the ethical ideal of care in the 21st century. Philosophy and Technology, 24, 254.

Van der Plas, A., Smits, M., \& Werhmann, C. (2010). Beyond speculative robot ethics: A vision assessment study on the future of the robotic caretaker. Accountability in Research, 17(6), 299-315.

Woolham, J. (2006). Safe at home-the effectiveness of assistive technology in supporting the independence of people with dementia: The safe at home project. London: Hawker Publications. 